\title{
FRACTURE RESISTANT PROPERTIES OF AERMET STEELS
}

\author{
L. C. CHHABILDAS*, W. D. REINHART*, M. E. KIPP*, T. F. THORNHILL**, \\ D. R. REEDAL ${ }^{* * *}$, L. T. WILSON ${ }^{* * *}$, and D. E. GRADY****
}

\begin{abstract}
*Sandia National Laboratories, Department 1610, P.O. Box 5800, Albuquerque NM 87185-1187, USA; ** Ktech Corp, 2201 Buena Vista, SE, Suite 400, Albuquerque NM 87106-4265, USA; ***Naval Surface Warfare Center, Dahlgren Division, Dahlgren, VA, 22448-5000, USA; ****Applied Research Associates, 4300 San Mateo Blvd., NE, A220 Albuquerque, NM 87110, USA
\end{abstract}

\begin{abstract}
The purpose of this study is to report well-controlled experiments conducted to determine the fracture resistant properties of AerMet 100 steels. One of the objectives of this study is to determine the influence of fracture toughness properties on the fracture and fragmentation process. Both sphere impact tests and cylinder expansion test geometry were used to determine the dynamic fracture resistant coefficients. These experiments were conducted at strain rates of $\sim 14 \times 10^{3} / \mathrm{s}$ for the cylinder expansion tests; the strain rates for the sphere impact tests varied over 50 to $100 \times 10^{3} / \mathrm{s}$. Fracture resistant coefficients of $60 \mathrm{Mpa} / \mathrm{m}$ and $20 \mathrm{Mpa} \sqrt{\mathrm{m}}$ are obtained from the cylinder test and the sphere impact test, respectively. These measurements do not agree with the static fracture toughness values reported in the literature.
\end{abstract}

\section{INTRODUCTION}

The destruction of metals under hypervelocity loading is critically dependent on the dynamic thermo-mechanical response in both compression and tension. Steel alloys are complicated further by stress-induced phase change and adiabatic shear banding. These features influence both the nature and the intensity of fracture and fragmentation in the hypervelocity regime. In the present study properties critical to dynamic fracture and fragmentation of specific (Aermet $\circledast 100$ ) steel are being investigated in detail to support computational model development and simulation.

To evaluate its fracture and fragmentation properties under multiaxial loading conditions, these experiments were conducted under well-controlled fracture and fragmentation test methodologies. One of these test techniques to examine dynamic failure and fracture fragmentation properties of solids involves controlled impulsive loading of a sphere. This is achieved by launching a sphere at high velocity against a thin low-impedance bumper shield. Both "as received" and heat-treated AerMet $₫ 100$ spheres are used in this test series. X-rays taken at strategic locations allow the determination of fragment velocities and size distributions. Grady-Kipp (Grady, Kipp 1996, 1997) fragmentation model is then used to calculate the dynamic fragmentation resistance of the fragmentation process.

The second test methodology used was an explosive test (Rice, Kreider, 1996) conducted on an 8" 8 " "as received" and heat-treated AerMet 8100 cylinder. The test included flash radiography, high-speed camera coverage, and fragment soft recovery. The flash radiography data provided fragment polar ejection angles and initial fragment velocities. The high-speed camera coverage recorded the case expansion. Fragment soft recovery was accomplished by using attapulgite clay and cellulose fiberboard bundles. This soft recovery allowed us to determine fragment mass and size distributions. Grady-Kipp (Grady, Kipp 1996, 1997) 


\section{DISCLAIMER}

This report was prepared as an account of work sponsored by an agency of the United States Government. Neither the United States Government nor any agency thereof, nor any of their employees, make any warranty, express or implied, or assumes any legal liability or responsibility for the accuracy, completeness, or usefulness of any information, apparatus, product, or process disclosed, or represents that its use would not infringe privately owned rights. Reference herein to any specific commercial product, process, or service by trade name, trademark, manufacturer, or otherwise does not necessarily constitute or imply its endorsement, recommendation, or favoring by the United States Government or any agency thereof. The views and opinions of authors expressed herein do not necessarily state or reflect those of the United States Government or any agency thereof. 


\section{DISCLAIMER}

Portions of this document may be illegible in electronic image products. Images are produced from the best available original document. 
fragmentation model is used to calculate the dynamic fragmentation resistance of the fragmentation process.

In order to design and then interpret the cylinder test described above, calculations were performed using the hydrodynamic code CTH. These calculations were some of the first to use the newly installed Grady-Kipp (Grady, Kipp 1996, 1997) fragmentation model in CTH. The initial fragment velocity and the mean fragment size/mass are compared to the actual test data. Results of these experiments and calculations will be discussed in terms of its dynamic material properties determined both under uniaxial-strain (spall) and multi-axial loading states, (fracture and fragmentation), and in terms of Grady-Kipp (Grady, Kipp 1996, 1997) model.

\section{MATERIAL}

AerMet $^{\circledR} 100$ steel can be heat-treated to various hardness levels to acquire tailored fractured toughness properties. In this study, we investigated the "as-received" and heat-treated material in order to compare the dynamic properties of the material as a function of its heat treatment properties (Carpenter Technology). The average density of the "as received" AerMet ${ }^{\otimes} 100$ material used in this study is $7.94 \pm .01 \mathrm{~g} / \mathrm{cm}^{3}$. The major alloying elements are nickel, chromium, molybdenum, and cobalt. The material is generally heat treated by performing a solution treatment, followed by quenching, and refrigeration. The material is then aged. When this procedure is followed, the material will have a nominal fracture toughness of $126 \mathrm{MPa} \sqrt{\mathrm{m}}$ and yield strength of $1724 \mathrm{MPa}$. In the "as received" condition, the material has a fracture toughness of $165 \mathrm{MPa} \sqrt{\mathrm{m}}_{\mathrm{m}}$ and yield strength of $1379 \mathrm{MPa}$ (Reinhart et al, 2000).

Using ultrasonic techniques, the average longitudinal and shear-wave speeds were determined to be $5.770 \mathrm{~km} / \mathrm{s}$ and $3.069 \mathrm{~km} / \mathrm{s}$, respectively, for the as-received samples, and 5.787 $\mathrm{km} / \mathrm{s}$ and $3.087 \mathrm{~km} / \mathrm{s}$, respectively, for the heat-treated samples. This yields a Poisson's ratio, $v$, of 0.302 for both materials. Results of plate-impact experiments (Reinhart et al, 2000) indicate that the dynamic yield strength of the "as-received" and heat-treated material is $0.75 \mathrm{GPa}$ and 1.8 $\mathrm{GPa}$, respectively. Both materials exhibit a solid to solid phase transformation. The phase transformation occurs at $12.5 \mathrm{GPa}$, and $15 \mathrm{GPa}$, respectively for the "as-received" and "heattreated" material. The estimates of the spall strength for the corresponding material are $5.3 \mathrm{GPa}$ and 7.5 GPa respectively, below the phase transformation stresses, and is approximately $20 \%$ higher for each material when spalled above the phase transformation stress. These results strongly suggest that the heat treatment process influence both the transformation kinetics and the spall properties of the material.

\section{SPHERE IMPACT TESTS}

There were two objectives to this series of sphere impact tests. First, is the comparison of as-received and heat-treated failure and fragmentation properties of AerMet ${ }^{\circledR} 100$ steel under ballistic impact loading conditions. The second objective was to determine the strain to failure or threshold impact velocity for this test geometry.

In the present series of tests, $9.53 \mathrm{~mm}$ diameter spheres of AerMet ${ }^{\otimes} 100$ steel were launched with a two-stage light gas gun and caused to undergo normal impact on thin plates of aluminum oxide ceramic (Lucalox), or fused silica. The tests were conducted at the Sandia National Laboratories (SNL) Star Facility (Asay et al 1981). Grady and Kipp $(1996,1997)$ provide a detailed description of the test method. Figure 1 shows the test setup. The catcher stack consists of alternating layers of paper reams and $1 \mathrm{~mm}$ thick copper plate. Flash radiography provided shadow-graphic images of the deformed spherical projectile or fragment debris at three stations downstream from the impact point. Because of the relatively high $\mathrm{x}$-ray opacity of the target 


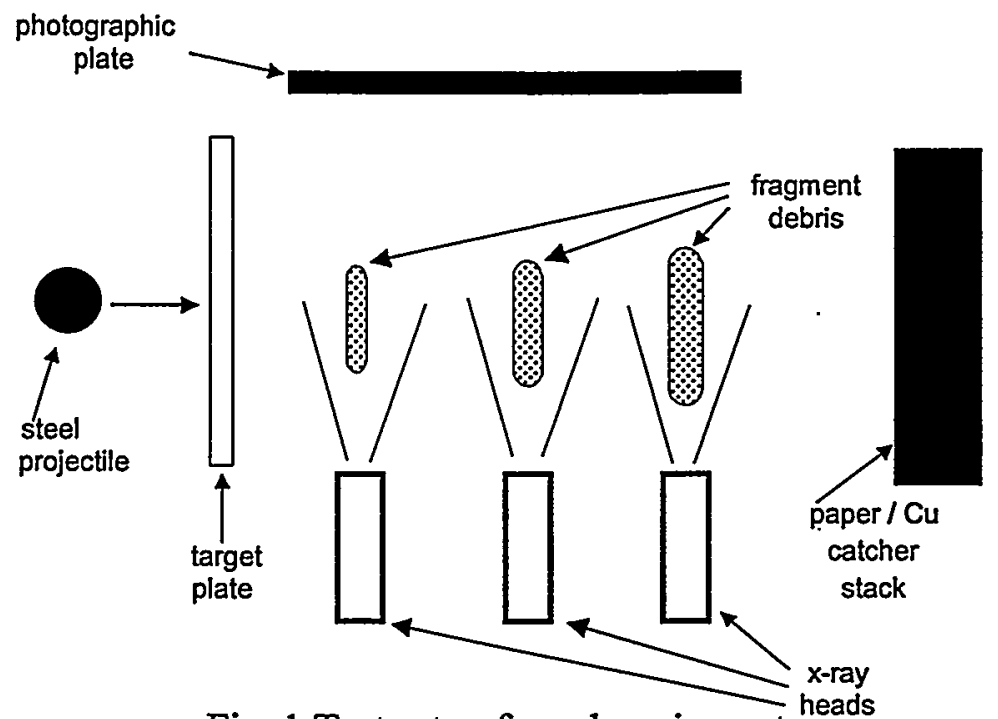

Fig. 1 Test setup for sphere impact

experiments.

plate debris, only the AerMet ${ }^{\circledR} 100$ steel is imaged. These radiographic data are then used to assess resulting consequences of the impact event including extent of deformation, breakup threshold, change in axial velocity, induced radial and axial expansion velocity, and fragment size distribution of the test sample. Radiographs from two AerMet ${ }^{\circledR} 100$ steel sphere experiment is shown in Figure 2.

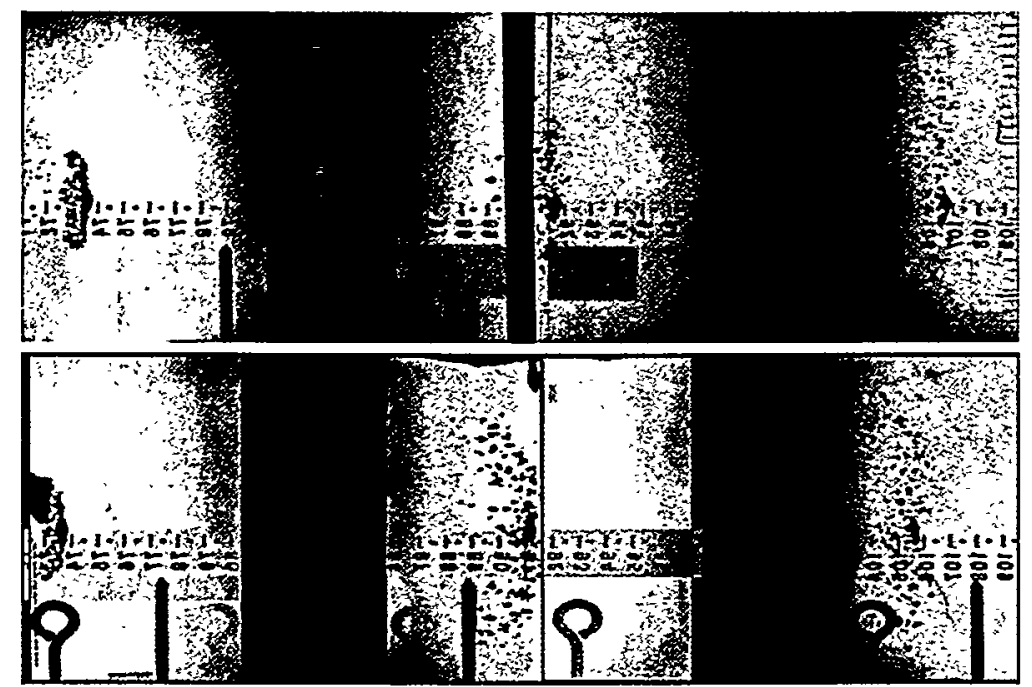

Fig. 2 Radiograph of Aerfrag -3 (top), Aerfrag-4 (bottom) AerMet ${ }^{\circledR} 100$ sphere fragmentation.

\section{Test Results}

To examine consequences of heat treatment on failure and fragmentation in the present impact experiments tests were duplicated using the as-received and heat-treated spheres. The radiographs are used to characterize the fragmented debris. In particular, the axial and radial 
expansion velocity, fragment size, and change in axial-velocity were determined. The axial expansion velocity is defined as the change in debris cloud thickness along the axis of flight divided by the time between radiographs. The radial expansion velocity is defined as the change in debris cloud diameter normal to the axis of flight divided by the time between radiographs. The change in axial velocity is defined as the impact velocity minus the change in axial position of the debris front divided by the time between radiographs. In experiments where failure of the test sphere did not occur, a measure of deformation strain was assessed. The deformation strain is defined (Grady, Kipp 1996) $\varepsilon_{\text {def }}=1-\left(I_{\text {axial }} / R\right.$ ) where $I_{\text {axial }}$ is the deformed sphere axial dimension and $R$ is the initial sphere diameter. Table 1 summarizes the results of these measurements. Characterization of the fragmentation results is carried out in the next section.

Table 1. Experimental Properties for Sphere Impact Tests

\begin{tabular}{|c|c|c|c|c|c|c|c|c|}
\hline $\begin{array}{l}\text { Test } \\
\text { No. }\end{array}$ & $\begin{array}{c}\text { Sphere } \\
\text { Heat } \\
\text { Treatment }\end{array}$ & $\begin{array}{c}\text { Target } \\
\text { Materia } \\
\quad l\end{array}$ & $\begin{array}{c}\text { Target } \\
\text { Plate } \\
\text { Thicknes } \\
s(\mathrm{~mm})\end{array}$ & $\begin{array}{c}\text { Impact } \\
\text { Vel. } \\
(\mathrm{km} / \mathrm{s})\end{array}$ & $\begin{array}{c}\text { Radial } \\
\text { Expansi } \\
\text { on Vel. } \\
(\mathrm{km} / \mathrm{s})\end{array}$ & $\begin{array}{c}\text { Axial } \\
\text { Expansi } \\
\text { on Vel. } \\
(\mathrm{km} / \mathrm{s})\end{array}$ & $\varepsilon_{d e f}$ & $\begin{array}{c}\text { Change } \\
\text { in Axial } \\
\text { Vel. } \\
(\mathrm{km} / \mathrm{s})\end{array}$ \\
\hline $\begin{array}{c}\text { Aerfrag- } \\
2\end{array}$ & $\begin{array}{c}\text { As } \\
\text { Received }\end{array}$ & $\mathrm{L}$ & 3.85 & 3.84 & 0.93 & 0.34 & -- & 0.71 \\
\hline $\begin{array}{c}\text { Aerfrag- } \\
3\end{array}$ & $\begin{array}{c}\text { As } \\
\text { Received }\end{array}$ & $\mathrm{L}$ & 3.82 & 3.83 & 1.13 & 0.33 & $-\cdots$ & 0.66 \\
\hline $\begin{array}{c}\text { Aerfrag- } \\
4\end{array}$ & Hardened & L & 3.81 & 3.90 & 1.04 & 0.54 & --- & 0.65 . \\
\hline $\begin{array}{c}\text { Aerfrag- } \\
5\end{array}$ & $\begin{array}{c}\text { As } \\
\text { Received }\end{array}$ & FS & 3.13 & 3.88 & 0.27 & 0.065 & -- & 0.31 \\
\hline $\begin{array}{c}\text { Aerfrag- } \\
6\end{array}$ & Hardened & FS & 3.17 & 3.86 & 0.21 & 0.022 & -- & 0.36 \\
\hline $\begin{array}{c}\text { Aerfrag- } \\
7\end{array}$ & $\begin{array}{c}\text { As } \\
\text { Received }\end{array}$ & FS & 3.81 & 3.46 & -- & -- & 0.26 & 0.38 \\
\hline $\begin{array}{c}\text { Aerfrag- } \\
8\end{array}$ & Hardened & FS & 3.84 & 3.59 & --- & -- & 0.18 & 0.39 \\
\hline $\begin{array}{c}\text { Aerfrag- } \\
10\end{array}$ & Hardened & $\mathrm{L}$ & 3.83 & 1.80 & -- & --- & 0.18 & 0.43 \\
\hline $\begin{array}{c}\text { Aerfrag- } \\
11\end{array}$ & $\begin{array}{c}\text { As } \\
\text { Received }\end{array}$ & $\mathrm{L}$ & 3.78 & 1.77 & -- & -- & 0.22 & 0.44 \\
\hline $\begin{array}{c}\text { Aerfrag- } \\
12\end{array}$ & Hardened & $\mathrm{L}$ & 3.80 & 2.27 & -- & -- & $0.17^{\mathrm{c}}$ & 0.48 \\
\hline $\begin{array}{c}\text { Aerfrag- } \\
13\end{array}$ & $\begin{array}{c}\text { As } \\
\text { Received }\end{array}$ & L & 3.92 & 2.19 & -- & -- & $0.31^{d}$ & b \\
\hline
\end{tabular}

${ }^{2}$ L-Lucalox, FS - Fused Silica

${ }^{b}$ No $x$-rays of test.

${ }^{c}$ Radiographs show a single deformed sphere with fracture formation visible.

${ }^{\mathrm{d}}$ No radiographs captured, measurements made on recovered deformed sphere.

Expansion Velocity. As observed in Figure 2, as the impulse imparted to the metal sphere exceeds some critical level, fragmentation occurs. The resulting disc of fragment debris undergoes axial and radial expansion. Radial expansion velocity is plotted as a function of impact velocity in Figure 3. Both fused silica and Lucalox target plates were used to fragment 
the sphere. Subsequent testing with fused silica required higher launch velocities to get the higher expansion velocity desired for an accurate fragment analysis. The use of Lucalox target plates allow sphere fragmentation to occur at lower impact velocities.

The data for AerMet ${ }^{\otimes} 100$ into fused silica indicate a threshold velocity of $3.1 \mathrm{~km} / \mathrm{s}<$ $\mathrm{IV}_{\text {threshold }}<3.8 \mathrm{~km} / \mathrm{s}$ is necessary to achieve failure and subsequent fragmentation of the test sphere. For hardened AerMet ${ }^{\circledR} 100$ into Lucalox the threshold velocity for fragmentation is

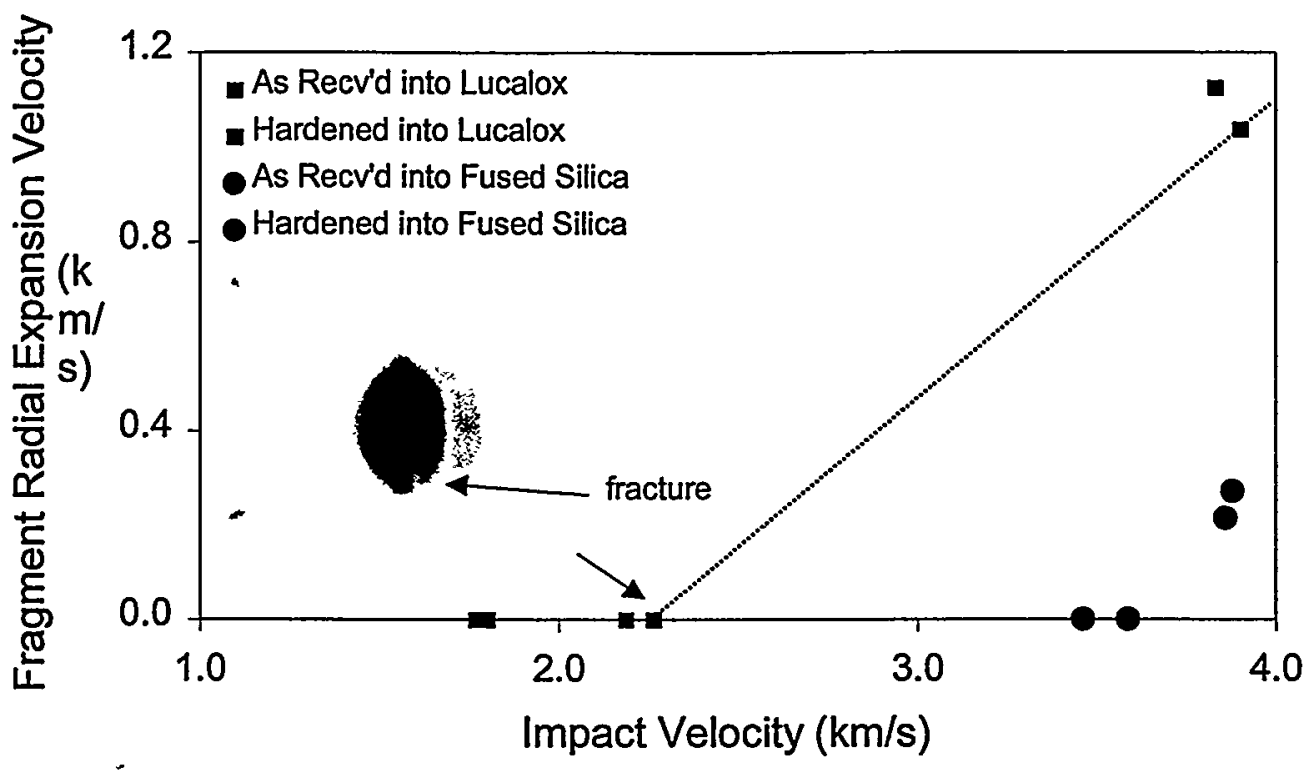

Fig. 3 Expansion Velocity versus Impact Velocity - AerMet ${ }^{\circledR} 100$ Sphere Fragmentation.

found to be $2.19 \mathrm{~km} / \mathrm{s}$. This threshold is determined from the radiograph in Figure 3 of shot Aerfrag-12 in which the sphere is seen as one deformed piece with a single radial fracture visible in the mass. Shot Aerfrag-13 is a repeat of Aerfrag-12 using the as received AerMet ${ }^{\circledR} 100$ sphere. No $\mathrm{x}$-rays were available for this shot, but the sphere was recovered in one piece. Based on this data the threshold velocity for the as received AerMet ${ }^{\circledast} 100$ appears to be slightly higher than the heat-treated material.

Failure Strain. In five tests, impact velocity did not exceed the threshold velocity and the sample, although deformed, showed no evidence of fragmentation. For these tests a

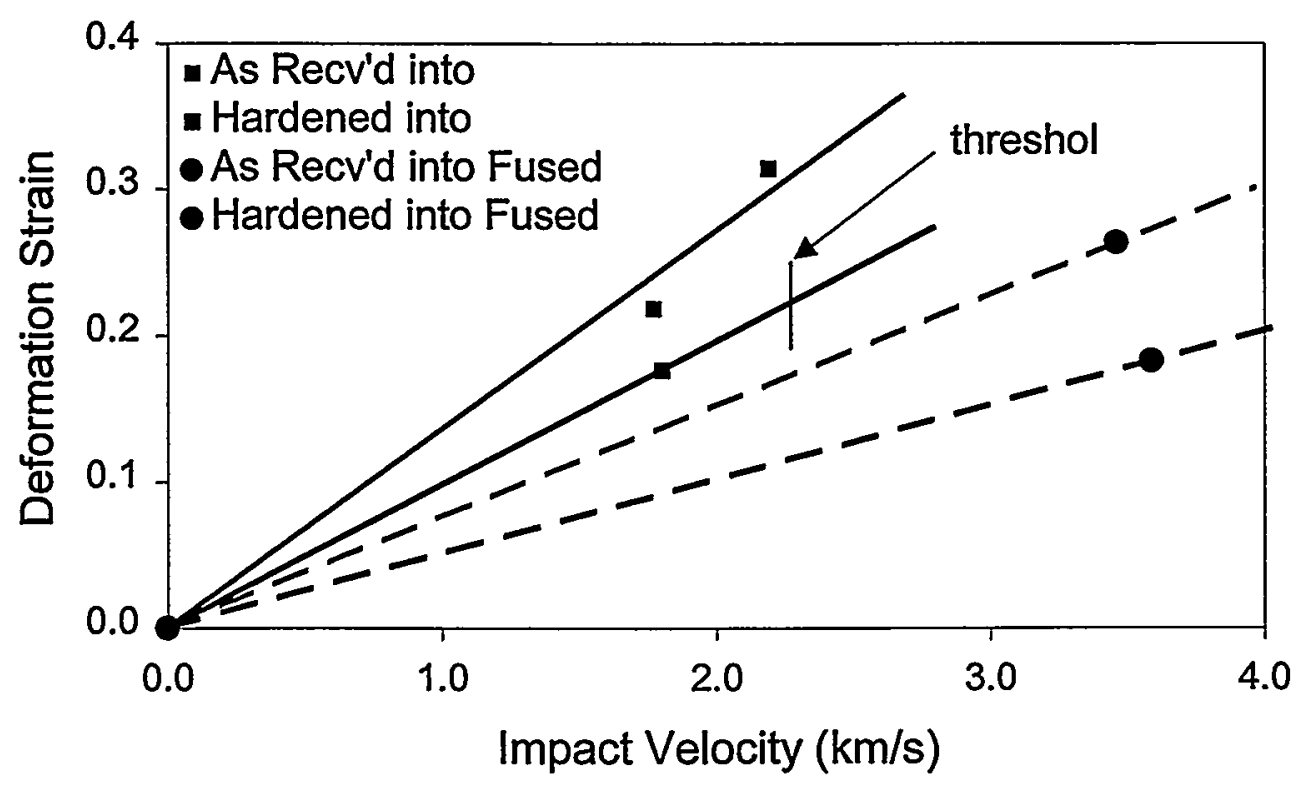

Fig. 4 Deformation strain for AerMet (B) 100 sphere impact 
consistent measure of deformation strain was determined from the radiographic data. Results for the as received, and hardened spheres launched into two target materials are plotted in Figure 4. The data for hardened AerMet ${ }^{\circledR} 100$ impacting Lucalox linearly extrapolated to the threshold impact velocity identifies a nominal strain to failure $\left(\varepsilon_{\text {fail }}\right)$. Linear extrapolation of the other shot configurations based on the slope of the trend lines in figure 4 identifies upper (lowest I.V. fragmented shot) and lower (highest I.V. unfragmented shot) bounds for strain to failure. These extrapolations are summarized in Table 2. As shown in table 2 the extrapolated strain to failure values vary slightly depending on the target material. These variations are due to the differences in loading rate and pulse width between the target materials.

Table II. Strain To Failure Values for AerMet ${ }^{\circledR} 100$ Sphere Impact Experiments

\begin{tabular}{|c|c|c|c|}
\hline Shot Configuration & $\varepsilon_{\text {fail }}$ & $\varepsilon_{\text {fail Lower Bound }}$ & $\varepsilon_{\text {fail }}$ Upper Bound \\
\hline $\begin{array}{c}\text { Hardened into Fused } \\
\text { Silica }\end{array}$ & --- & 0.18 & 0.20 \\
\hline $\begin{array}{c}\text { As Received into Fused } \\
\text { Silica }\end{array}$ & -- & 0.27 & 0.29 \\
\hline Hardened into Lucalox & 0.22 & -- & -- \\
\hline As Received into Lucalox & -- & 0.29 & 0.52 \\
\hline
\end{tabular}

The tests resulting in fragmentation are used to determine the maximum axial and radial strain rates based on Equation (1).

$$
\dot{\mathcal{E}}_{\text {axial }}=\frac{V_{\text {axial }}}{R_{\text {axial }}}, \text { or } \quad \dot{\mathcal{E}}_{\text {radial }}=\frac{V_{\text {radial }}}{R_{\text {radial }}}
$$

$\mathrm{V}$ is defined as the axial or radial fragment debris cloud expansion velocity, and $\mathrm{R}$ is defined as the deformed sphere axial or radial dimension measured in shots Aerfrag-12 and 13. Table 3 summarizes these measurements.

Table III. Strain Rate Values for Fragmented AerMet ${ }^{\circledR} 100$ Sphere Impact Experiments

\begin{tabular}{|c|c|c|c|}
\hline Shot Number & $\dot{\mathcal{E}}_{\text {axial }}\left(S^{-1}\right)$ & $\dot{\mathcal{E}}_{\text {radial }}\left(S^{1}\right)$ & $\dot{\mathcal{E}}_{\text {total }}\left(S^{-1}\right)$ \\
\hline Aerfrag-2 & $52 \times 10^{3}$ & $79 \times 10^{3}$ & $95 \times 10^{3}$ \\
\hline Aerfrag-3 & $51 \times 10^{3}$ & $97 \times 10^{3}$ & $110 \times 10^{3}$ \\
\hline Aerfrag-4 & $68 \times 10^{3}$ & $83 \times 10^{3}$ & $107 \times 10^{3}$ \\
\hline Aerfrag-5 & $10 \times 10^{3}$ & $23 \times 10^{3}$ & $25 \times 10^{3}$ \\
\hline Aerfrag-6 & $2.8 \times 10^{3}$ & $17 \times 10^{3}$ & $17 \times 10^{3}$ \\
\hline
\end{tabular}

\section{Fragmentation Analysis and Results}

Recovery of fragments from sphere impact tests to assess particle size and statistics is not practical because of the high residual fragment velocity. The catcher stack was refined during the test series and fragment recovery by mass ranged from $60 \%$ to $98 \%$. Shot Aerfrag- 12 shows an unchanging intact sphere in the radiographs, catcher stack recovery is primarily five large pieces with tens of smaller fragments. Consequently, effects of the catcher stack on fragment size can not be quantified so radiography of the fragments behind the point of impact is used to estimate size characteristics. Two tests, Aerfrag-3 and Aerfrag-4 because of their higher axial and radial fragment cloud expansion velocities are used for fragment analysis. In these tests, the 
higher expansion velocities and the longer free flight distance of the third radiograph minimizes fragment overlap.

Fragment size analysis is performed by scanning the third radiograph from the selected shot. Spatial calibration is applied to the digital files yielding a resolution of $0.0009 \mathrm{~mm}^{2}$ for one pixel. Fragments are then identified based on "color", counted, and sized. Figure 5 shows histograms of fragment area for shots Aerfrag-3 and 4. Comparison of the histograms indicates greater numbers of small fragments for the as received sample.

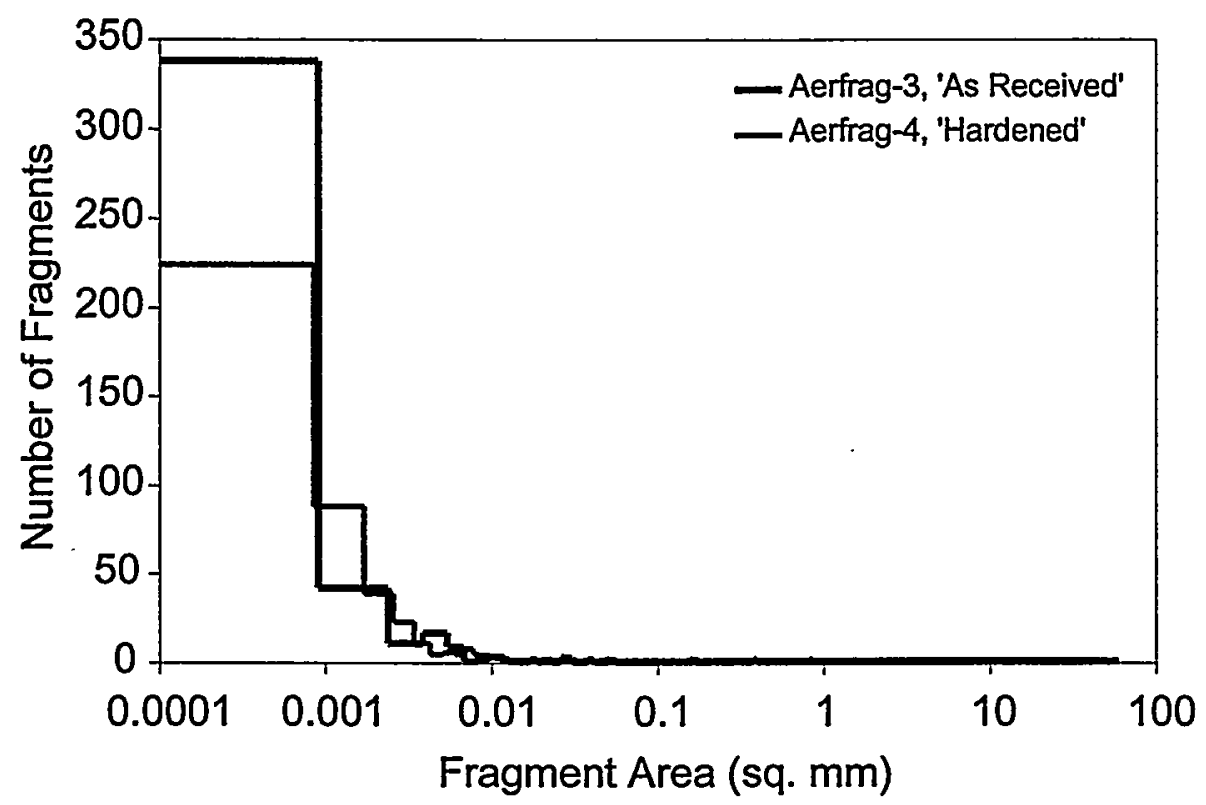

Fig. 5 Fragment size histograms for Aerfrag -3 and 4.

Poisson Statistical Analysis and Fragment Toughness. As suggested by Grady and Kipp the total fragment area vs. fragment areal size can be represented by a bilinear exponential (Grady, Kipp, 1996) of the form

$$
N=N_{0}^{l} e^{-\lambda A}+N_{0}^{s} e^{-\xi A}
$$

A measure of dynamic fragmentation toughness $K_{f}$ has been developed in an energy-based theory of dynamic fragmentation of solids [Grady, 1988]. Equation 3 gives the relationship of $\mathrm{K}_{\mathrm{f}}$ to fragment size and expansion strain rate. The use of two exponentials to represent the

AerFrag3, As Received Aermet100 into Lucalox Target

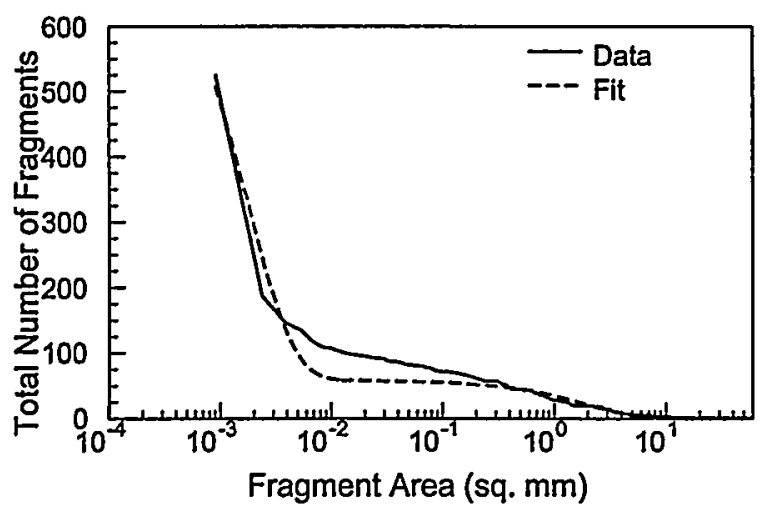

Aerfrag4, Hardened Aermet 100 into Lucalox Target

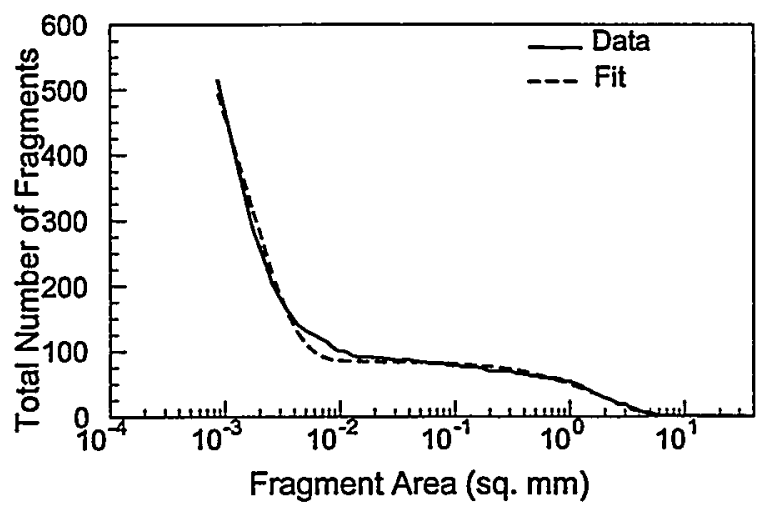

Fig. 6 Total fragments vs. fragment area. 
fragment distribution assumes that two different strain rates dominate the fragmentation process. The first term represents the large fragments associated with the lower strain-rate fragmentation process, presumably the axial strain-rate. The second term represents the smaller fragments associated with perhaps the higher radial strain rates. Based on Poisson statistics (Grady, Kipp, 1996), the coefficients $\lambda$ and $\xi$ represent the reciprocal of the mean fragment size for the large and small fragments respectively, and the coefficients $\mathrm{N}_{0}{ }^{1}$ and $\mathrm{N}_{0}{ }^{5}$ represent the number of large and small fragments in equation (2). Figure 6 plots Aerfrag-3 and Aerfrag-4 cumulative fragments vs. fragment area as well as their respective bilinear exponential fits. Results of the fit are given in Table 4.

Table 4. Bilinear Exponential Fit Coefficients

\begin{tabular}{|c|c|c|c|c|}
\hline Shot Number & $N_{0}^{l}$ & $\lambda\left(\mathrm{mm}^{-2}\right)$ & $N_{0}^{s}$ & $\xi\left(\mathrm{mm}^{-2}\right)$ \\
\hline Aerfrag-3 & 58.1 & 0.51 & 769 & 586 \\
\hline Aerfrag-4 & 84.8 & 0.55 & 726 & 652 \\
\hline
\end{tabular}

A measure of dynamic fragmentation toughness $\mathrm{K}_{\mathrm{f}}$ has been developed in an energy-based theory of dynamic fragmentation of solids [Grady, 1988]. Equation 3 gives the relationship of $K_{f}$ to fragment size and expansion strain rate. Applying Equation 3 to the strain rate measurements and fragment size derived from $\lambda$ assuming a spherical fragment yields the fragmentation toughness values shown in Table 5 .

$$
K_{f}=\frac{\rho c \dot{\varepsilon} S^{\frac{3}{2}}}{\sqrt{24}}
$$

Table 5. Poisson's Statistics Fragmentation Toughness for AerMet ${ }^{\circledR} 10.0$ Sphere Impact Experiments

\begin{tabular}{|c|c|c|c|}
\hline Shot Number & $\begin{array}{c}\text { Strain Rate For } \\
\text { Calculation }\left(\mathrm{s}^{-1}\right)\end{array}$ & $\begin{array}{c}\text { Fragment Diameter } \\
S(\mathrm{~mm})\end{array}$ & $K_{f}\left(\mathrm{MPa} \mathrm{m}^{1 / 2}\right)$ \\
\hline Aerfrag-3 & $51 \times 10^{3}$ & 1.58 & 23 \\
\hline Aerfrag-4 & $68 \times 10^{3}$ & 1.53 & 29 \\
\hline
\end{tabular}

The relatively large variation in fragmentation toughness for the large and small mean fragment size suggests a large variation of strain rates effect the fragmentation process. This is evident in the radiographs when looking at the fragment spatial distribution. The larger fragments tend to show small expansion velocities and the fragment size tends to get smaller as one moves outward toward the edges of the fragment debris cloud. Most of the original mass and kinetic energy of the sphere is intact in the larger area fragments; therefore the fracture toughness calculation using the large fragments is more pertinent to this study.

Arithmetic Mean Analysis and Fragment Toughness. The Poisson's analysis of fragmentation toughness is low when compared to the nominal expected fragmentation toughness values reported in the manufacturer literature (Carpenter Technology, 19xx). Using the radiograph fragment size histogram data to calculate an arithmetic mean fragment size yields fragmentation toughness numbers closer to the nominal values. Table 6 summarizes these calculations. 
The mean fragment diameter S (Eq. 3) is calculated assuming spherical shaped fragment projecting a circular fragment area in the radiograph. In addition the large central area in the fragment debris cloud is counted as a single fragment in the digital analysis. This large area is

Table VI. Arithmetic Mean Fragmentation Toughness for AerMet ${ }^{\oplus} 100$ Sphere Impact Experiments

\begin{tabular}{|c|c|c|c|}
\hline Shot Number & $\begin{array}{c}\text { Strain Rate For } \\
\text { Calculation }\left(\mathrm{s}^{-1}\right)\end{array}$ & $\begin{array}{c}\text { Fragment Diameter } S \\
(\mathrm{~mm})\end{array}$ & $K_{f}\left(\mathrm{MPa} \mathrm{m}^{1 / 2}\right)$ \\
\hline Aerfrag-3 & $51 \times 10^{3}$ & 5.94 & 170 \\
\hline Aerfrag-4 & $68 \times 10^{3}$ & 6.07 & 234 \\
\hline
\end{tabular}

believed to be four to six large overlapping fragments based on the fragment recovery. However, statistically it would not change the Poisson's fit appreciably.

\section{Discussion of Sphere Fragmentation Tests}

The results presented show an experimentally measured difference in AerMet ${ }^{\circledR} 100$ steel undergoing well-controlled fracture and fragmentation test methodologies. Measured fragmentation toughness compares well with nominal manufacturers (Carpenter Technology, $19 \mathrm{xx}$ ) values. Poisson statistical analysis of fragment size distribution suggests a range of strain rates at work in this experimental configuration. The failure threshold velocity is defined for two different loading conditions, and the hardened material has a consistently lower threshold.

In this test series the fragment size distribution is measured directly from the radiographs without relying on fragment recovery, or a statistical determination of fragment size $\mathrm{S}$ from the total volume of the fragmented material in the debris cloud. Fragment overlap is minimized by maximizing the expansion velocities, and fragment free flight distance of the radiograph. Unquantified sources of error in this technique are; The distribution of fragments relative to the $\mathrm{x}$-ray head and film location. Placing the film as close as possible to the debris cloud, and moving the $\mathrm{x}$-ray head as far back as possible minimizes this error. In addition, statistically it is assumed the fragments are uniformly distributed about the axis of flight helping to negate differences in film magnification due to spatial orientation. Advantages of this technique are the ease of digital analysis, and the ability to account for very small fragments.

\section{CYLINDER EXPANSION TESTS}

The fragment formation accompanying expansion of a cylinder that has been accelerated with explosives has been discussed in many places (e.g., Mock and Holt, 1983; Mott, 1943). Much work has been invested in understanding the fragmentation process and predicting fragment characteristics that ensue. In the present study, fragmentation of a high-strength Aermet steel alloy is examined under conditions of an expanding cylindrical geometry, accelerated by an explosive charge.

Numerical simulations of the devices were made with the CTH Eulerian shock wave propagation code (McGlaun, et al., 1990). This multi-dimensional shock physics Eulerian code is capable of modeling dynamic events that include explosive detonation and high velocity impact. The CTH code solves the differential equations describing conservation of mass, momentum and energy during transient dynamic events on a fixed spatial mesh. CTH is capable of tracking the interactions of up to 20 materials. This code contains models suitable to describe material response under most conditions encountered in shock physics, including the explosives and inert solids for the current application. A variety of material insert geometries facilitate the modeling of complex devices. The 
Eulerian structure of the code permits large deformations associated with explosive or impact events to be accommodated. The characteristic fragment dimensions in the numerical simulations are determined principally by the strain rate, , at the time of fracture. The basic relationships between the strain rate and the average fragment dimensions that result as materials fracture under high strain rate loading conditions have been derived by Grady (1988). In the current analyses, the temperature and strain rate regimes are such that the fragmentation is governed by the fragmentation toughness, $\mathrm{K}_{\mathrm{F}}$, of the materials. The average fragment size, $\mathrm{S}$, is then determined from equation 3 .

This fragment information is included in the simulation, but does not couple back into the calculation to form discrete fragments (Kipp, et al., 1993). The calculation is triggered when the Johnson-Cook failure model, used as a 2-parameter pressure dependent strain to failure model, indicates that the material has reached failure (Johnson and Cook, 1985). Currently, the numerical simulation models material fracture by introducing void into a cell to affect the unloading from a tensile state to a state of zero stress. As was shown by Grady and Benson (1983) and Kipp and Grady (1986), a uniform strain rate leads to a single average fragment size, but an essentially Poisson distribution of sizes about that mean. This principle is applied here to the local average sizes calculated by the code to obtain a final statistical fragment distribution.

\section{Description of Experiments}

The cylinder expansion experiments described here are part of a continuing series of tests designed to quantify the fragmentation characteristics of high strength metals. The test results of the AerMet@ 100 material are from an ongoing experimental program. The objectives of this test are to study the cylinder expansion prior to and including case rupture, quantify the initial fragment velocity, and determine the fragment mass distribution.

The test hardware consisted of a heat-treated AerMet(B) 100 steel cylinder. Each cylinder was $20.3 \mathrm{~cm}$ in length and had a $20.3 \mathrm{~cm}$ inner diameter. The charge to mass ratio was chosen to

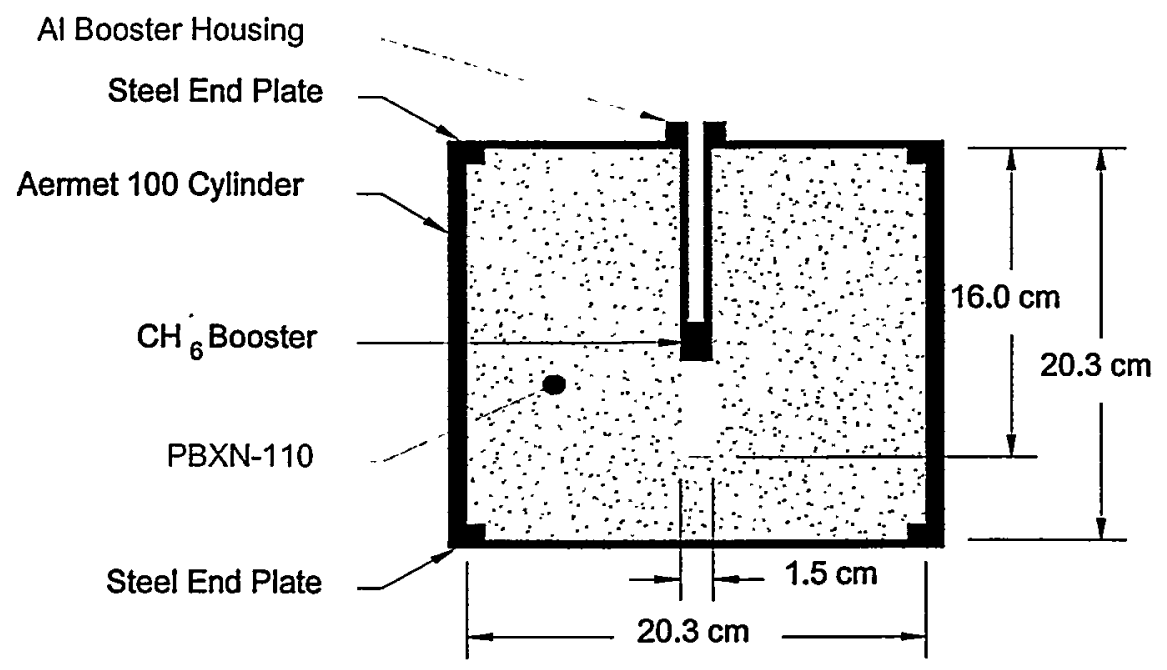

Fig. 7 Hardware geometry.

be near unity. The main charge explosive, PBXN-110, was center initiated with a $\mathrm{CH}-6$ booster. The unit was confined with steel end plates. A sketch of the test units is shown in Figure 7. Specific dimensions for the test unit are located in Table 7. 
Table 7. Specific Dimensions for Test Unit

\begin{tabular}{|c|c|}
\hline & AerMet 100 \\
\hline Density & $7940 \mathrm{~kg} / \mathrm{m}^{3}$ \\
\hline Inner Diameter & $20.32 \mathrm{~cm}$ \\
\hline Outer Diameter & $21.97 \mathrm{~cm}$ \\
\hline Wall Thickness & $0.82 \mathrm{~cm}$ \\
\hline Cylinder Mass & $8.85 \mathrm{~kg}$ \\
\hline Explosive Mass & $10.15 \mathrm{~kg}$ \\
\hline
\end{tabular}

The test setup included a high-speed framing camera, flash radiography, and soft fragment recovery. The high-speed framing camera recorded case expansion and onset of fracture. The flash radiography provided fragment velocity and polar ejection angle distribution. The soft fragment recovery was used to collect fragments in order to determine fragment mass distribution. The fragments were collected from a $25^{\circ}$ azimuthal sector of the cylinder. A sketch of the test setup is provided in Figure 8.

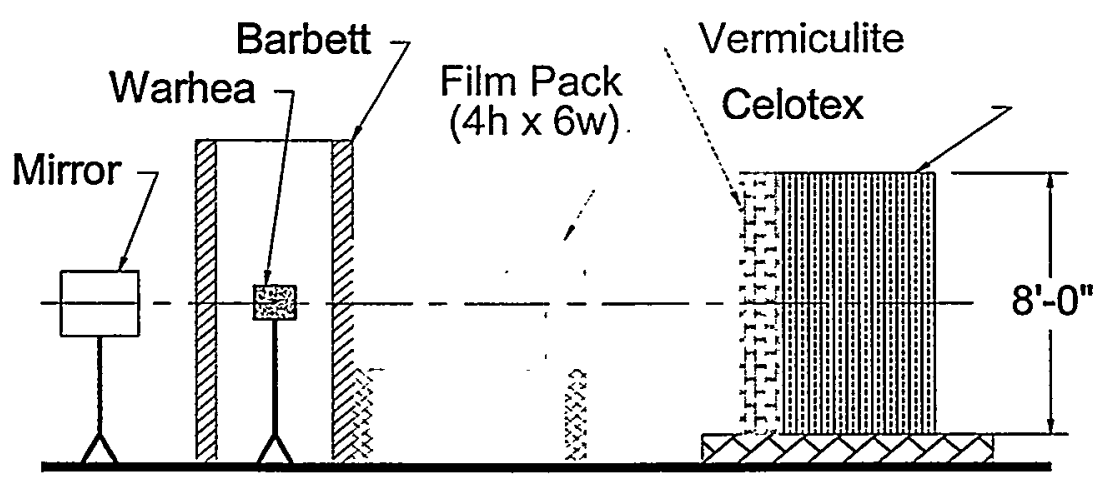

Fig. 8 Test setup.

\section{Numerical Simulations and Corresponding Test Data}

The axisymmetric simulations had a uniform numerical resolution of $0.5 \mathrm{~mm}$. The explosive parameters for the PETN booster were for a density of $1.77 \mathrm{~g} / \mathrm{cm}^{3}$, with a detonation velocity of $8.3 \mathrm{~km} / \mathrm{s}$ as defined by Dobratz and Crawford, (1985). The main charge used for AerMet@ 100 steel experiments was PBXN-110, represented here with either the HMX explosive PBX-9404 or Composition B3, both simulated with a reactive burn model. The cylinder walls were modeled assuming an elastic perfectly plastic constitutive response (where the plastic flow stresses were obtained from split Hopkinson pressure bar measurements) and Mie Gruneissen equations of state (LANL, 1969). In the current CTH implementation, the fracture model uses the JohnsonCook failure model (Johnson and Cook, 1985) as a 2-parameter pressure dependent strain to failure model. The two damage parameters needed for our calculations were estimated using a combination of experimental results and handbook values for spall stress, strain to failure, and quasi-static fracture stress. The needed $\mathrm{K}_{\mathrm{F}}$ parameter of Equation 4 was estimated using the result of the experiment. Material model parameters are provided in Appendix A. 
The Cylinder Expansion Experiment. The cross-section of the axisymmetric numerical representation of the AerMet $\circledast 100$ steel experiment and the corresponding framing camera results are shown in Figures 9 through 11. Note that in the axisymmetric representation, pressure contours are on the left and material plots are on the right. The central region of the AerMet $\mathbb{B}$
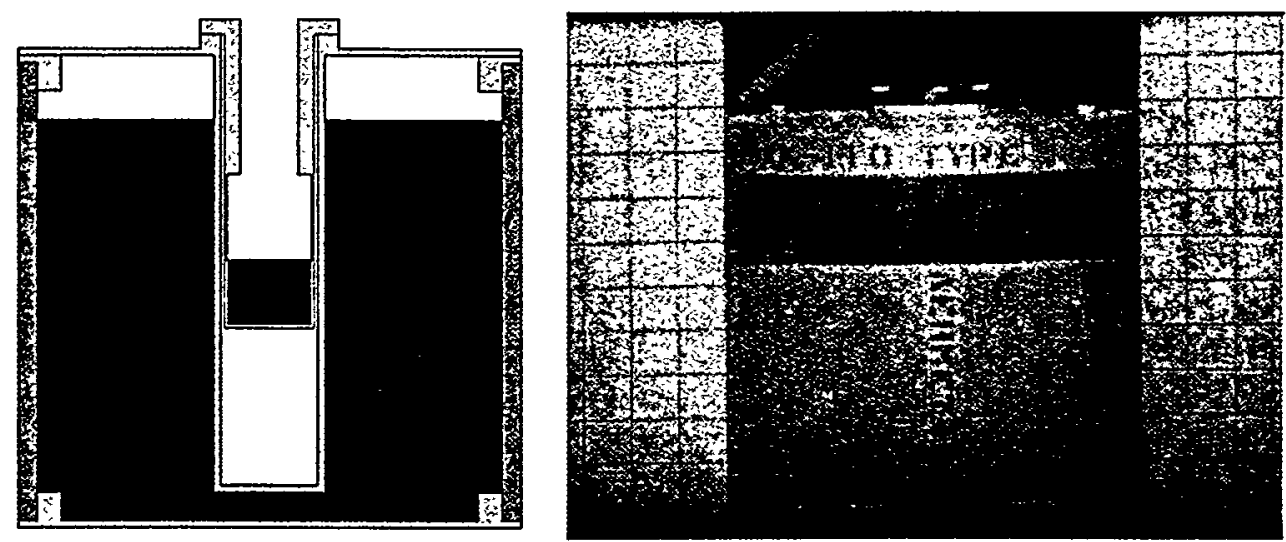

Fig. 9 Comparison of CTH calculation and AerMet 100 steel cylinder at $\mathrm{T}=0 \mu \mathrm{s}$.
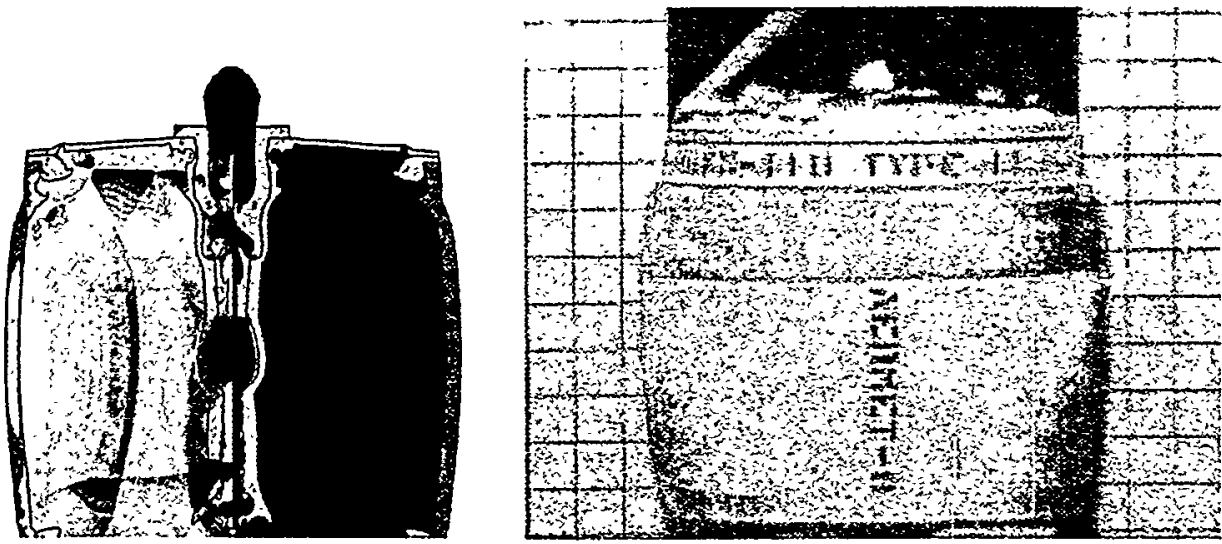

Fig. 10 Comparison of CTH calculation and AerMet 100 steel cylinder at $\mathrm{T}=25$
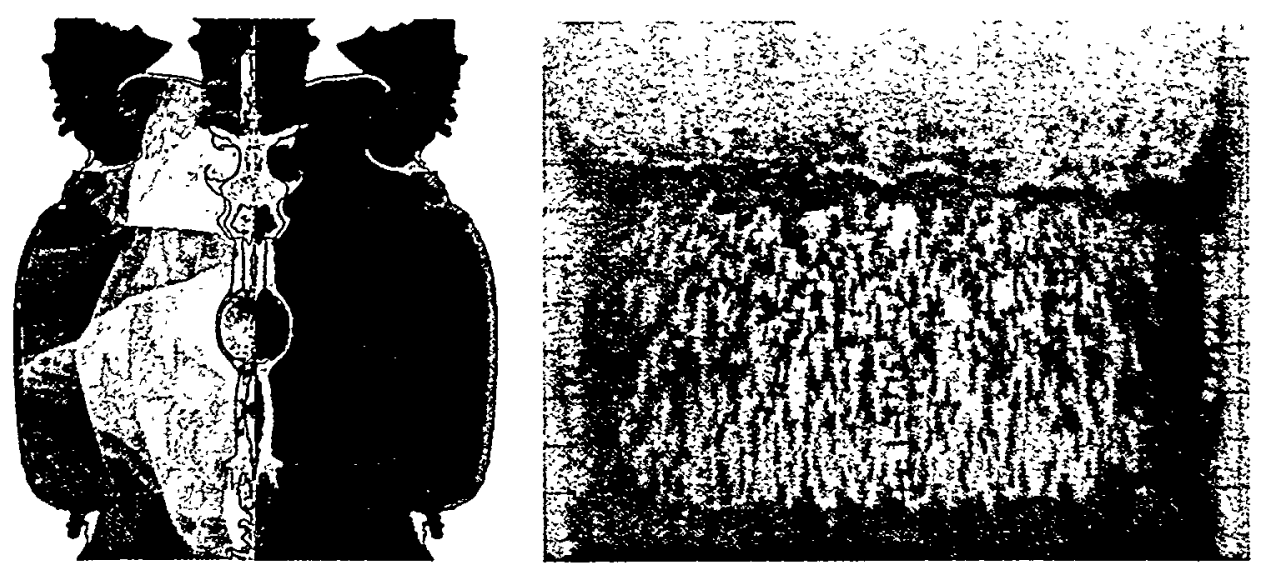

Fig. 11 Comparison of $\mathrm{CTH}$ calculation AerMet 100 steel cylinder at $\mathrm{T}=50_{\mu} \mathrm{s}$. 
100 steel cylinder experiences the first radial outward motion. As the curved front of the detonation wave expands along the cylinder wall, the wall assumes the curved shape seen in Figures 10 and 11 at 25 and $50 \mu \mathrm{s}$. Once again, the experimental external cylinder contours correlate well with the computational predictions.

Figure 12 shows the recovered fragments from the test. The average fragment size of

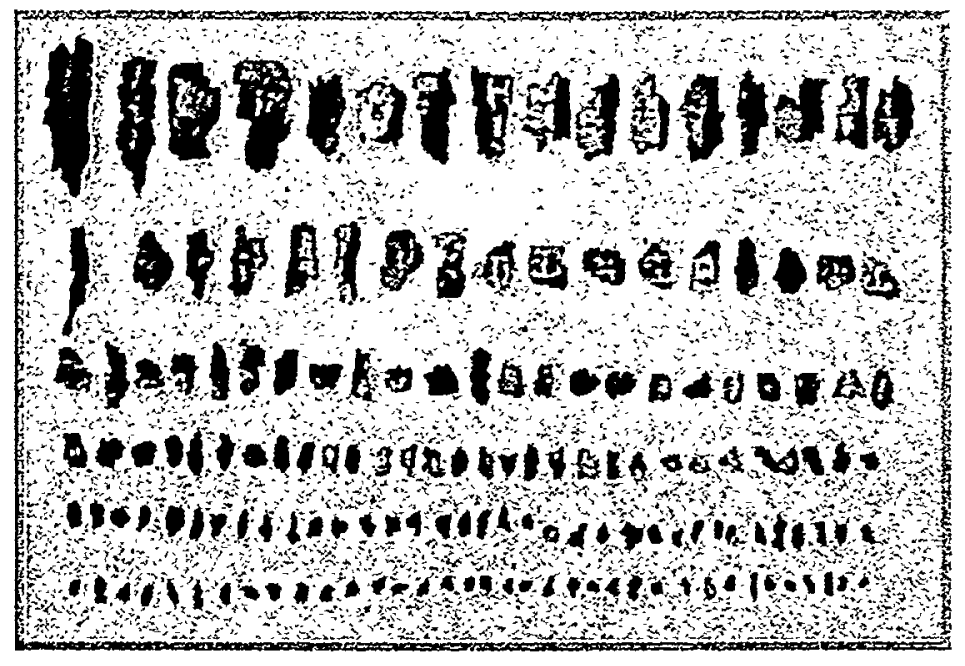

Fig. 12 Fragments recovered from the AerMet 100 steel cylinder test.
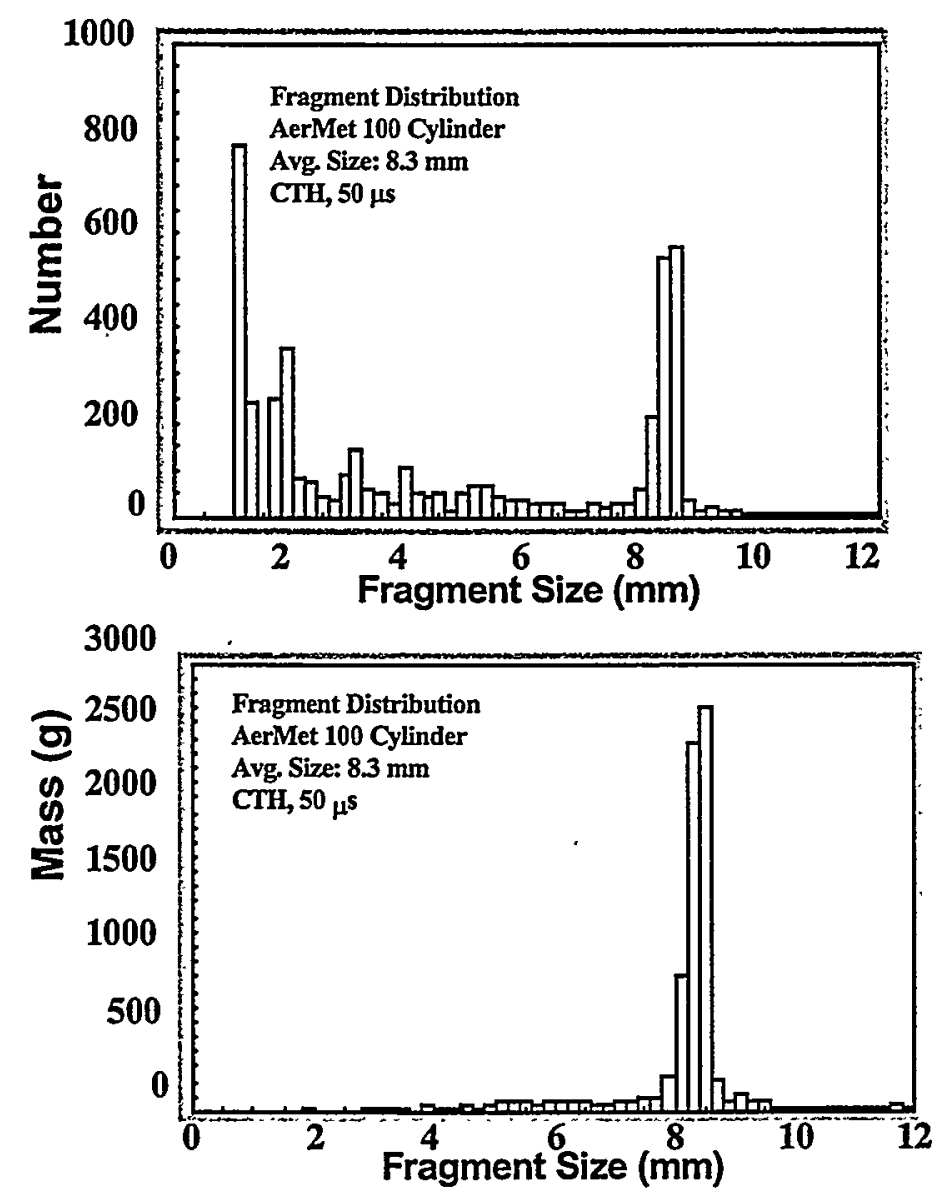

Fig. 13 Fragment number (top) and mass (bottom) distributions for the AerMet 100 steel cylinder (fragment bin size $0.2 \mathrm{~mm}$ ). 
about $8 \mathrm{~mm}$, indicated in the distributions (Figure 13), leads to a fragment mass of about $4.5 \mathrm{~g}$ ( 70 grains). The average mass value from the experimental data is 51 grains when an exponential distribution is assumed. There is a disparity in circumferential and axial strain rates, leading to axial sizes of nearly $20 \mathrm{~mm}$ for an aspect ratio of 2.5 . Combining this dimension with the local thickness at failure (about $7 \mathrm{~mm}$ ), and the circumferential dimension of about $8 \mathrm{~mm}$, a fragment mass of about $9 \mathrm{~g}$ (140 grains) is calculated. For these thicker steel shells, Mock and Holt (1983) found that there were many fragments that did not extend through to both the inner and outer surfaces. It is the intent of the statistical distribution associated with the local average fragment size to accommodate such contributions to the overall fragment size distribution.

Figure 14 compares the cumulative mass distribution that is predicted using CTH with that experimentally determined. Once again, there is significant disparity in the results when only

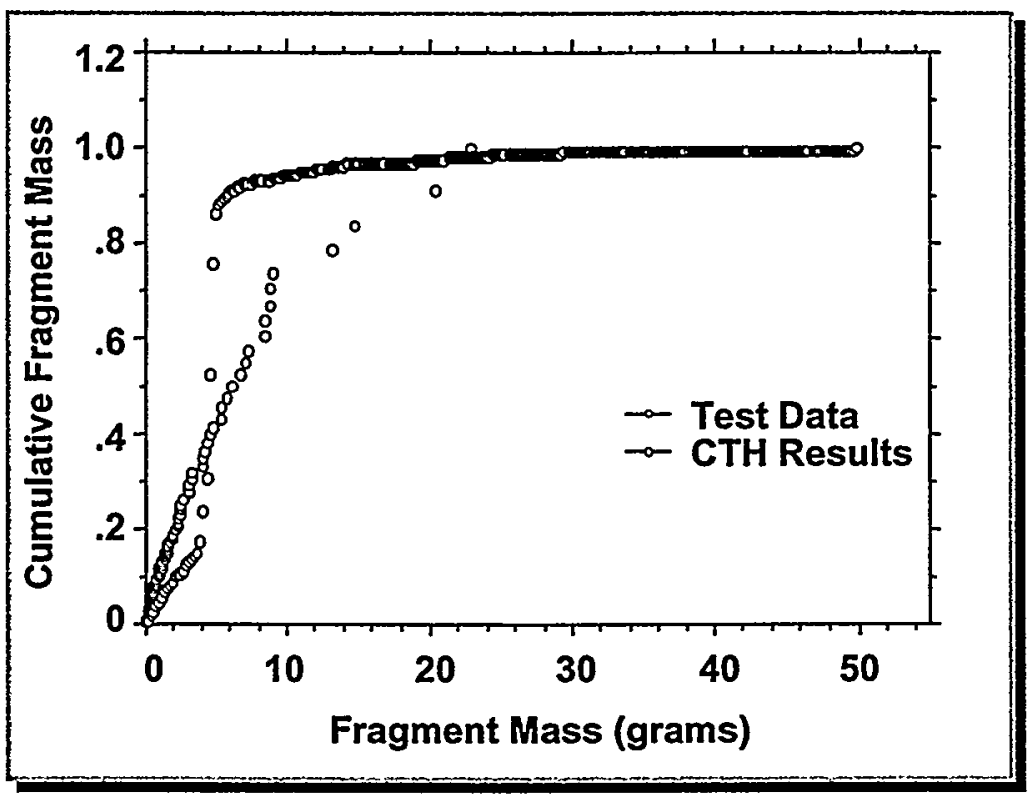

Fig. 14 Experimental and calculated fragment cumulative mass distribution.

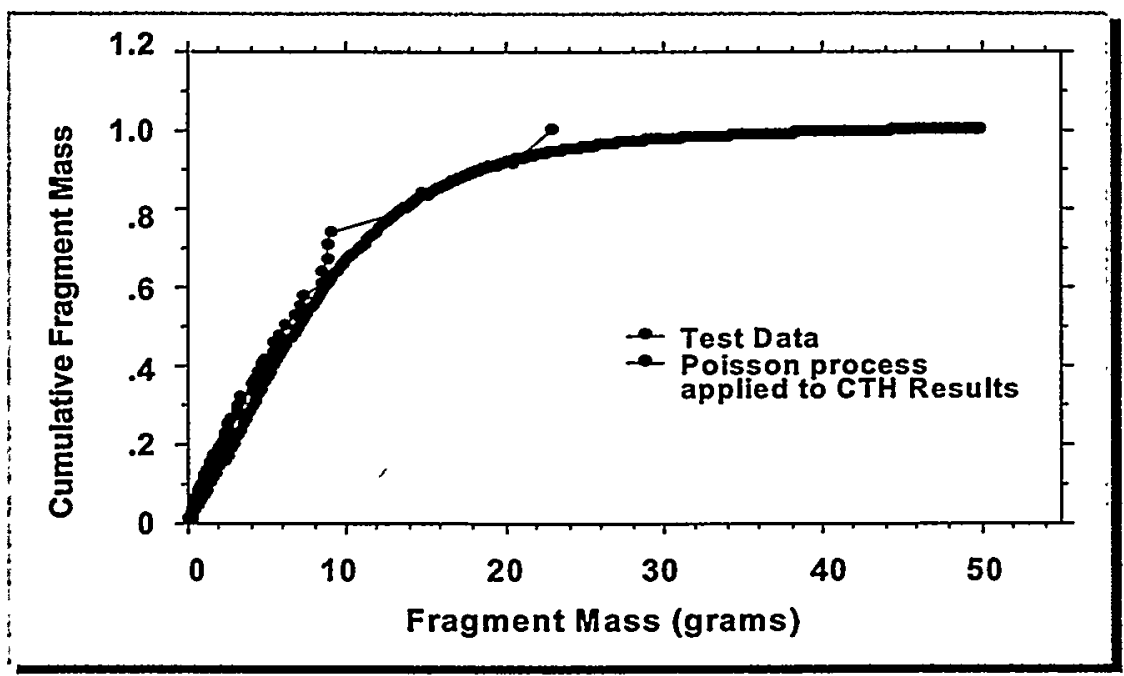

Fig. 15 Experimental and post processed calculated fragment cumulative mass distribution. 
the local average fragment size is considered. As can be seen, the CTH prediction shows that most of the fragment mass is concentrated in a few fragment bins, a consequence of the narrow range of strain rates present in the cylinder. This results in a much steeper rise to the distribution that is not physically correct. By imposing a Poisson distribution on each of the fragment bins, and summing these distributions results in much better agreement with the experimental data (Figure 15).

\section{Discussion of Cylinder Expansion Tests}

The results presented indicate that the Grady-Kipp fracture and fragmentation model, as implemented into CTH, provides reasonable estimates of average fragment mass. However, these average measures do not provide results that match the experimentally determined cumulative mass distributions. When Poisson statistics are applied to the local average fragment sizes, the agreement between the numerical and experimental results improves dramatically. This is especially encouraging, since the two materials studied are so dissimilar in nature.

In the future, we would like to improve the coupling of the Poisson statistics within the model. We would also like to accommodate multiple local strain rates and case thickness in a more inclusive way in order to determine fragment size distributions. Addressing multiple local strain rates is especially important for predicting the response of a material like steel where large "strip" fragments are generally produced. It is important to address the effects of case thickness because fragments may tend to break preferentially into sizes based upon wall thickness; and, because fragmentation occurs later in cylinders expanding under internal explosive loads than under free expansion. The internal pressure reduces the tensile stress, particularly on the interior of the cylinder adjacent to the explosive, and delays the formation of sufficient tensions to fracture. These improvements would allow implementation of a physically consistent, easy to use fragmentation model into $\mathrm{CTH}$.

\section{SUMMARY}

The material properties parameters used for numerical simulation of the cylinder expansion tests are provided in Appendix A. A value of $\sim 60 \mathrm{Mpa} \sqrt{\mathrm{m}}$ was used for fragmetation toughness in these simulations. This was determined experimentally using equation 3 and the observed strain-rate of $\sim 14 \times 10^{3} / \mathrm{s}$ and the mean fragment size observed in the cylinder test. The sphere impact tests however yield a fragmentation toughness of $\sim 25 \mathrm{Mpa} \sqrt{\mathrm{m}}$ based on Poisson's statistics at a strain rate of $\sim 50 \times 10^{3} / \mathrm{s}$. It appears that statistically, the difference between the as-received and heat-treated samples are not quite significant. More significantly, both these measurements do not agree with static measurements of fracture toughness of $\sim 130$ Mpa $\sqrt{\mathrm{m}}$ reported in the literature. These results are consistent with previous fragmentation studies on a tungsten alloy (Reedal et al 1999), in that the fracture toughness values obtained using sphere impact tests are an order of magnitude lower than static and cylinder expansion tests. The reasons for this discrepancy are not clear. It is conceivable that the stress state in the sphere impact tests which leads to the fragmentation process is considerably different than those obtained in the cylinder tests. This also raises the possibility that the fracture toughness values may it self be strain-rate dependent. Further investigation is necessary and currently underway to pursue these concepts. 


\section{ACKNOWLEDGMENTS}

The authors wish to recognize the following people for their contributions. Mr. J. F. Liwski and Mr. J. R. Martinez of Ktech Corp. for their support of the two-stage gas gun sphere fragmentation tests. Ms. Lucia Kuhns of NSWCDD for her technical contributions on the AerMet@ 100 steel cylinder test data. This work performed at Sandia National Laboratories supported by the U.S. DOE under contract DE-AC04-94AL85000.

\section{APPENDIX A: MATERIAL MODEL PARAMETERS}

The material parameters used for the AerMet® 100 steel in the cylinder test calculations are summarized in this appendix. The equations of state referenced a linear shock velocity particle velocity Hugoniot, and the parameters for these materials are listed in Table A1. The solid materials were all treated with an elastic-perfectly plastic constant yield strength model. These parameters are listed in Table A2. The spall stress for each material is listed in Table A3. The Johnson-Cook fracture model (Johnson and Cook, 1985) was used to model the failure of the cylinder wall in expansion. This model permits the fracture stress to decay from the initial spall stress to the uniaxial tensile stress at maximum elongation, a practical application to accommodate both high strain rate fracture accompanying relief wave interactions (spall) and much lower rate case expansion. The model is used with only pressure dependence,

$$
\varepsilon_{\mathrm{f}}=D_{2} \cdot \exp \left(-D_{3} P / Y\right)
$$

where $\varepsilon_{f}$ is the strain to failure, $D_{2}$ and $D_{3}$ are constants, $P$ is the pressure, and $Y$ is the yield strength. The parameters are included in Table A3. The fragmentation model requires the toughness for these materials, which are also listed in Table A3

Table A1. Equation of State Parameters

\begin{tabular}{|c|c|}
\hline Parameter & AerMet $@ 100$ \\
\hline Density $\left(\mathrm{g} / \mathrm{cm}^{3}\right)$ & 7.94 \\
\hline Sound Speed $(\mathrm{cm} / \mathrm{s})$ & $4.529 \times 10^{5}$ \\
\hline Linear $\mathrm{U}_{\mathbf{s}} \mathrm{u}_{\mathrm{p}}$ Coefficient & 1.50 \\
\hline Gruneissen Constant & 1.84 \\
\hline Specific Heat (ergs/g/eV) & $5.183 \times 10^{10}$ \\
\hline
\end{tabular}

Table A2. Yield Parameters

\begin{tabular}{|c|c|}
\hline Parameter & AerMet@100 \\
\hline Yield Stress (dynes $\left./ \mathrm{cm}^{2}\right)$ & $25.9 \times 10^{9}$ \\
\hline Poisson's Ratio & 0.302 \\
\hline Melt Temperature (eV) & 0.20 \\
\hline
\end{tabular}


- Table A3. Fracture Parameters

\begin{tabular}{|c|c|}
\hline Parameter & AerMet@100 \\
\hline Spall Stress (dynes/cm²) & $-75.0 \times 10^{9}$ \\
\hline 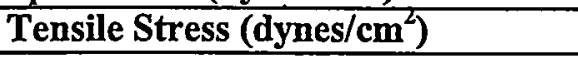 & $20.0 \times 10^{9}$ \\
\hline Elongation (\%) & 14 \\
\hline D2 (J-C Coefficient) & 0.156 \\
\hline D3 (J-C Coefficient) & -0.296 \\
\hline 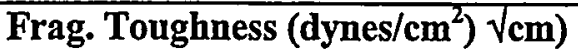 & $6 \times 10^{9}$ \\
\hline
\end{tabular}

\section{REFERENCES}

[1] Carpenter Technology Corporation, Alloy Data Sheets, AerMet ${ }^{\circledast} 100$

[2] Dobratz, B. M. and P. C. Crawford (1985). "LLNL Explosives Handbook. Properties of Chemical Explosives and Explosive Simulants", Lawrence Livermore National Laboratory Report, UCRL- 52997, Change 2, January 1985.

[3] Grady, D. E. and Kipp M. E. (1996). "Impact Failure and Fragmentation Properties of Metals", Sandia National Laboratories Report, SANDxx-xxxx, 1996

[4] Grady, D. E. (1988). “The Spall Strength of Condensed Matter”, J. Mech. Phys. Solids, 36, 353- 384.

[5] Grady, D. E. and D. A. Benson (1983). "Fragmentation of Metal Rings by Electromagnetic Loading", Experimental Mechanics, 23, 393-400.

[6] Grady, D. E. and M. E. Kipp (1985). “Geometric Statistics and Dynamic Fragmentation”, J. Appl. Phys., 58, 12101222.

[7] Group GMX-6 (1969). "Selected Hugoniots", Los Alamos Scientific Laboratory Report LA- 4167-MS.

[8] Johnson , G. R. and W. H. Cook (1985). "Fracture Characteristics of Three Metals Subjected to Various Strains, Strain Rates, Temperatures and Pressures", Engineering Fracture Mechanics, 21, 31-48.

[9] Kipp, M. E. and D. E. Grady (1986). "Random Flaw Nucleation and Interaction in One Dimension", in Metallurgical Applications of Shock-Wave and High-Strain-Rate Phenomena", Ed/ L. E. Murr, et al., Marcel Dekker, New York.

[10] Kipp, M. E., D. E. Grady, and J. W. Swegle (1993). "Experimental and Numerical Studies of High-Velocity Impact Fragmentation", Sandia National Laboratories Report, SAND93-0773, August 1993.

[11] McGlaun, J. M., S. L. Thompson, and M. G. Elrick (1990). "CTH: A Three-Dimensional Shock Wave Physics Code", Int. J. Impact Engng., 10, 351-360.

[12] Mock, W. and W. H. Holt (1983). "Fragmentation Behavior of Armco Iron and HF-1 Steel Explosive-Filled Cylinders", J. Appl. Phys., 54, 2344-2351.

[13] Mott, N. F. (1943). “A Theory of the Fragmentation of Shells and Bombs", British Ministry of Supply Report A. C. 4035.

[14] Rice, D .J., Kreider, W., Garnett, C., Wilson, L.T., (1996), Comparing Fragmentation Characteristics of Tungsten, Tantalum, and Steel, Proceedings of the $16^{\text {th }}$ International Symposium on Ballistics, San Francisco, CA.

[15] Reinhart, W. D., Chhabildas, L. C., Wilson, L. T., (2000) "Dynamic Yield Strength and Spall Strength Determination for AerMet 100 Steels," in Shock Compression of Condensed Matter-1999, ed. by M. D. Furnish, L. C. Chhabildas, R. S. Hixson, AIP Conf. Proceedings 505.

[16] Reedal, D. L., Wilson, L. T., Grady, D. E., Chhabildas, L. C., Reinhart, W. D. (1999) "Impact And Explosion Induced Failure And Fragmentation Studies On Tungsten", $15^{\text {th }}$ US Army Symposium on Solid Mechanics, Myrtle Beach, SC. 